\title{
Towards a Framework for Decision Making Regarding IT
}

\section{Adoption}

\author{
Osden Jokonya \\ School of Computing \\ University of South Africa \\ PO Box 392, UNISA, 0003 \\ Preller Street, Muckleneuk Ridge \\ Pretoria, South Africa \\ Tel. +27733919863 \\ Fax. +2786 6275497 \\ jokonyao@hotmail.com
}

\author{
Jan H. Kroeze \\ School of Computing \\ University of South Africa \\ PO Box 392, UNISA, 0003 \\ Preller Street, Muckleneuk Ridge \\ Pretoria, South Africa \\ Tel. +27 124296976 \\ Fax. +27865874127 \\ kroezjh@unisa.ac.za
}

\author{
John A. van der Poll \\ School of Computing \\ University of South Africa \\ PO Box 392, UNISA, 0003 \\ Preller Street, Muckleneuk Ridge \\ Pretoria, South Africa \\ Tel: +27 124296230 \\ Fax: +27 124296771 \\ vdpolja@unisa.ac.za
}

\begin{abstract}
Information Technology (IT) adoption challenges facing organizations are too complex to be resolved using only one methodology. Most existing Information Technology (IT) adoption models such as the Technology Acceptance Model (TAM) only consider individual behaviour and views on technology adoption, without providing mechanisms to accommodate multiple stakeholder perspectives in an organization. In this paper we propose an IT adoption framework, expected to assist an organization in resolving problem situations from multiple perspectives. Our framework provides mechanisms for addressing conflict of interest among stakeholders, which is rather common with IT adoption in organizations.
\end{abstract}

\section{Categories and Subject Descriptors}

H.1.1 [System and Information theory]: General systems theory - systems thinking, systems approaches; H.1.2 [User/Machine Systems]: Human factors - perceived ease of use and usefulness; H.5.3 [Group and Organization Interfaces]: Theory and models - systems theory, IT adoption models, stakeholder theory; J.4 [Social and Behavioral Sciences]: Psychology, Sociology - perceptions, assumptions, paradigms, and worldviews

\section{General Terms}

Diffusion of Innovation Theory, Technology Organization Environment Theory, Human Environmental Model, IT Governance

\section{Keywords}

Technology Acceptance Model, IT Adoption, Stakeholder, Sociological Paradigms, Systems Approaches

Permission to make digital or hard copies of part or all of this work for personal or classroom use is granted without fee provided that copies are not made or distributed for profit or commercial advantage and that copies bear this notice and the full citation on the first page. Copyrights for components of this work owned by others than ACM must be honored. Abstracting with credit is permitted. To copy otherwise, to republish, to post on servers or to redistribute to lists, requires prior specific permission and/or a fee.

SAICSIT '12, October 01 - 03 2012, Pretoria, South Africa Copyright 2012 ACM 978-1-4503-1308-7/12/10...\$15.00.

\section{INTRODUCTION}

According to the literature there are still some knowledge gaps and disparities in thinking with regard to Information Technologies (IT) adoption in organizations. IT adoption denotes the taking and execution of a conscious decision to use a particular technology from an individual or an organizational perspective in the organization [36]. Diffusion in turn is the decision to implement such technology after adoption [42]. Naturally any IT adoption ought to be done for the benefit of the organization [28].

Information Technologies have long been identified as a key factor in competitiveness and have even radically modified the basis of competition [5]. The influence of IT determines the competitive posture of many businesses in most countries globally [5]. However, the literature on IT is often characterized by an assumption that the benefits of such technology are selfevident, and that decision makers realize what is needed is to adopt the specific technology in an organization [5].

According to previous research e.g. [6], it has become sufficiently clear that the adoption of a new technology does not always result in all the anticipated benefits from the investment. The sustained investment and deployment of modern technology have increased interest in the study of IT adoption. Although technology adoption has been extensively researched, understanding IT adoption decision making is still one of the most challenging issues in IT research [5]. The importance of understanding the IT adoption decision making process in organizations has been highlighted by many researchers [2, 24].

The paper proposes an IT adoption decision making framework to assist with complex technology adoption in organizations. The rudimentary framework is developed by considering and improving on the various shortcomings of existing frameworks to complex problem situations facing organizations. A literature review identified some of the weaknesses of existing frameworks as a motivation for a new framework.

The layout of the paper is as follows: Section 2 of this paper discusses the existing models and their shortcomings to the challenges of IT adoption decision making while Section 3 investigates how stakeholder approaches assist IT adoption in organizations. Section 4 discusses the sociological paradigms of social theory with regard to different assumptions about problem situations. Section 5 discusses the systems approaches methodologies to address problem situations in organizations. The enhanced framework is presented in Section 6, and Section 7 concludes the paper. 


\section{IT ADOPTION DECISION MAKING}

Many studies have provided insights into the factors and reasons that influence IT adoption decisions in organizations [5, 36]. Despite numerous writings on IT adoption, studies indicate that an IT adoption decision-making problem still persists [27, 28]. Questions about the suitability of existing frameworks for IT adoption decision making have prompted much research in recent years. The present IT adoption decision-making frameworks do not seem to address the problems faced by many organizations, e.g. failing to understand how a framework may facilitate IT adoption decision making [27].

\subsection{Technology Acceptance Model (TAM)}

Despite the use of the Technology Acceptance Model (TAM) by Davis [12] and its extended models which provide insights into individual user behaviour on technology acceptance, TAM lacks a mechanism for considering the perspectives of multiple stakeholders and their involvement in IT adoption decision making in organizations [24]. The inability of TAM to address diverse perceptions of stakeholders and expectations is detrimental to IT adoption success in an organization. TAM models are deterministic in nature because they fail to recognize the importance of different stakeholder worldviews which is part of IT adoption and the use of technology in organizations [24].

The TAM model is suitable for individual users rather than for an organizational environment with multiple stakeholders [24]. Although TAM has been found, arguably, to be the most influential theory in IT adoption, it has been criticized for diverting the attention of researchers away from other important issues on IT adoption [2]. Most TAM studies reiterate the importance of perceived usefulness without investing much effort in trying to investigate what makes a system useful [2]. Some researchers have criticized TAM dominance as a paradigm for creating a narrow slice of the IT adoption domain [2]. The perceived usefulness of a TAM construct is also subjective from an organizational context, since individuals have different perceptions of the utility of technology.

The application of TAM to new technology is not clear about which features are perceived as being useful or not, in order to improve the design [2]. There is a need for more IT adoption theories suitable for the complex IT contexts to provide researchers with creative tools for IT adoption in organizations [2]. While TAM is useful, the model needs to be integrated with other variables related to human and social change processes in IT adoption [22].

\subsection{Diffusion of Innovation (DOI) Theory}

The diffusion of Innovation theory by Rogers, (1995) is one of the most popular models for understanding IT adoption decision making in organization based on its five stages. Despite diffusion of innovation theory's popularity its bias towards the technological component of the adoption process while ignoring other issues has been criticized by many researchers [4]. The criticism of diffusion of innovation theory is that IT adoption in organizations goes beyond technical factors but also includes social, economic and political factors. The diffusion of innovation theory needs further expansion to include other important factors.

The classic diffusion of innovation theory by Rogers (1995) has also been criticized for ignoring the social context of IT adoption in organizations as well as being too simplistic to address issues of social context in which the adoption and diffusion of IT take place [14]. The limitation of mechanistic causal relationships to socially construct IT adoption in organizations is the failure to understand the human environment and organizational context [14]. In order for IT adoption to be successful there is a need for social and environmental perspectives to complement technical perspectives [42]. IT adoption processes need to be based on social-technical adoption models instead of a technological linear phenomenon [42].

\subsection{Technology-Organization-Environment (TOE) Theory}

The technology, organization, and environment (TOE) framework by Tornatsky and Fleischer [37] on IT adoption in organizations is influenced by three elements namely technology context, organizational context and environmental context [4]. The technology context element's influence is based on the characteristics of technology available for adoption and the state of technology in the organization, the nature existence of technology material and their use in the organization. The organizational context element includes the size, structure, process, resources and behaviour of top management. The environment context element includes the existence of external support for the new technology, the government regulation and market structure.

The interaction of the three elements with each other has an influence on IT adoption in organizations [4]. Although the (TOE) theory has been successful in classifying adoption factors in their respective context it has been criticized for failure to provide a model for describing the factors that influence IT adoption decision making in organizations [4]. The technology-organization-theory's main contribution has been to encourage researchers to broaden context on IT adoption in organizations.

\subsection{The Human Environmental Model}

The human environmental model to IT adoption provides a holistic framework with a broader perspective to address sociotechnical issues associated with the complex IT adoption in an organization [42]. Du Plooy's [14] extended framework which adds six characteristics to an IT adoption process has been criticized for being too deterministic in assuming that the inclusion or use of social factors leads to an IT adoption exercise being successful [42].

In many situations the decision to adopt technology is made by top management without consulting individuals in the organization [42]. From an IT adoption perspective there is often no voluntary adoption as it is normally prescribed by top management [42]. Politics also have a major influence on IT adoption decision making in organizations [42]

\subsection{IT Governance}

Although IT governance as a framework may improve controls with respect to the alignment of IT and business objectives, it pays less attention to how IT adoption decisions are made [30]. Amongst other things, IT governance is tasked with deciding on how decision rights and accountability are distributed in organizations to avoid ad hoc decision making [17]. In order to improve IT governance in an organization, Weill [43] proposes the assignment of decision rights to five IT decision areas (architecture, infrastructure, principle, applications and investment) in an organization. The assignment of responsibilities and roles to decision-making domain areas helps to achieve a balanced governance structure for IT adoption decisions [22].

A major challenge for IT governance is the lack of understanding of how decisions are made in order to achieve 
business objectives [44]. Organizations need frameworks to address the IT requirements of different stakeholders in an organization [44]; hence IT adoption processes need to involve all stakeholders in the organization [17]. An important factor of an IT governance decision-making process is determining where in the organization decisions are made [43]. IT governance needs to promote the participation and engagement of stakeholders in IT adoption issues in organizations [39].

\subsection{Conclusion}

Evidence from the literature suggests that to achieve sustainable IT adoption benefits in organizations remains a problem [28]. The ever-increasing use of IT and the diversity of applications result in making decisions on IT adoption a major challenge to organizations [5]. The implicit assumption in most frameworks is that there is always consensus in IT adoption decisions [19]. The decision of using a particular technology from an organizational perspective is problematic since individual users have different worldviews [36]. Most of the studies on IT adoption have been based on a positivist paradigm with primary focus on the perception of individual uses with little attention given to multiple stakeholders in the organization.

\section{STAKEHOLDER APPROACH}

A major challenge is to decide who makes decisions on IT adoption issues in an organization. Many researchers have questioned whether IT adoption decisions are made in the interest of executives or other stakeholders [11, 28]. Stakeholders are defined as individuals or groups with an organizational interest and who may be impacted by the decisions [15]. Although stakeholder theory has been widely accepted in the information systems research, examination of the impact of stakeholder conflicts in IT adoption is relatively new [11].

Most IT adoption frameworks are too deterministic by assuming that stakeholders will automatically see the benefits of IT adoption in organizations [42]. Benefits of most IT adoptions in organizations are not obvious to all stakeholders due to different perspectives. Many researchers have highlighted the importance of stakeholder participation in the success of IT adoption [32], hence the involvement and participation of stakeholders have been found desirable in IT adoption decision making [20]. Therefore, it is vital to involve stakeholders with very opposing interests in the IT adoption decision-making processes [28, 36, 38].

IT adoption failure has been attributed to the independent creation of decisions, away from the social context and an inadequate exploring of stakeholder requirements $[3,11,26,28$, 40]. The independent creation of IT adoption decisions away from the social context of their use results in a gap between actual needs and official requirements [1]. In a world characterized by diverse worldviews, consensus on IT adoption decision making has become a challenge to many organizations $[11,17]$. Organizations have been urged to also focus on meeting user requirements when adopting new systems [24, 25, 41].

According to Lyytinen and Newman [25], deciding on who determines the important factors to consider during adoptions is important to IT adoption decision making. Organizations have been urged to use a bottom up approach as it facilitates the finding of solutions for those closest to the problem situation [1]. A user-centered design approach has been recommended for accepting user inputs and in turn communicating decisions back to the affected end users $[1,36]$.
Stakeholder participation refers to stakeholder involvement in decisions on IT adoption [36]. Stakeholder participation from a theoretical perspective appears simple, however in many cases designers view users as passive actors, underestimating their potential contribution to IT adoption success [36]. While managers are worried about the cost of an adoption exercise, users are more concerned with functionality and service [17]. IT adoption requires a holistic approach with equal participation of stakeholders in decision making and empowering stakeholders through the creation of a rich relationship that bridges complex multi-stakeholder differences [41]. Holistic changes require new ways of thinking towards the whole system and the examination of deep structures of the system [18, 41].

\section{SOCIOLOGICAL PARADIGMS}

Burrell and Morgan [7] claim that sociological paradigms of social theory can be classified into the categories: functionalist, interpretive, radical structuralism and radical humanism as shown in Figure 1. Sociological paradigms have been classified into four categories based on the nature of reality (subjectiveobjective) and the aspect of social order (radical change regulation). The assumptions of objectivists are that realities are independent of individual as they are external to individuals. The assumption of the subjectivist is that reality is socially constructed and is not independent to the individual who may interpret differently (subjectively). The assumptions of regulation are based on the perception of social order. Radical change assumption is that there is oppression of individuals in the society characterised by dominating forces.

These sociological paradigms are not mutually exclusive, yet offer a reasonable guideline as to where the main emphasis of an approach lies and to what managerial end it lends itself. The adoption of these sociological paradigms affects the way organizations perceive a problem situation and assists the management to better understand the sociological underpinnings of organizational theory [7]. The framework topology is based on regulation-radical changes and subjectiveobjective axes shown in Figure 1. The two dimensions yields four distinctive sociological clusters with each paradigm based on certain assumption on how individuals or groups accept evidence.

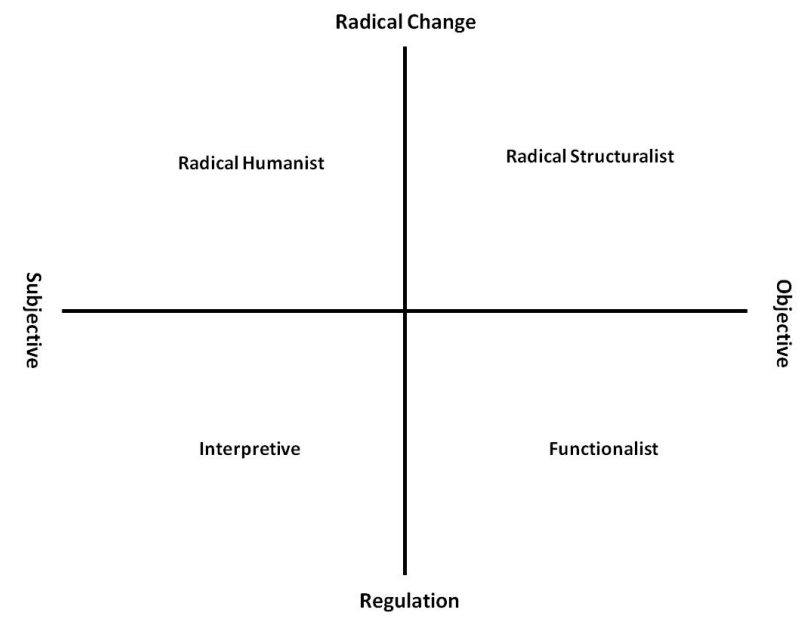

Figure 1. Four sociological paradigms [7].

The paradigm is a way of classifying similar theorist perspectives together in ways they approach a problem situation [7]. In order for individuals to change their ways of thinking they first need to abandon their old worldview [29]. In order to understand a different paradigm we need to change from the taken-for-granted assumptions. The existence of multiple 
paradigms is therefore to expand our perception of the knowledge base. It is important to consider multiple paradigms when studying a complex social phenomenon such as IT adoption decision making in organization as each paradigm emphasises and highlights different, though overlapping, aspects of the phenomenon. Furthermore, each paradigm emphasises different sources of data and different analytical approaches [5].

\subsection{The Functionalist Paradigm (Objective- regulation)}

This is the most popular paradigm based on the assumption that human actions are rational and organizational behaviour can be hypothesized. The intervention goal of this paradigm is to help individuals or group to adapt to the existing structures without the need for major institutional structure change [16]. Society is assumed to have shared values that help establish social order to the benefit of every member. The functionalist paradigm is based on the assumption that organizations are stable and rarely undergo a radical change. In addition to that reality is taken as a given and associated with standard and rational decision making.

The assumption of a stable and orderly entity leads to emphasis of a high degree of planning, the perception of physical boundaries and hierarchical organisational structure [16]. The functionalist paradigm assumes a stable organizational environment and is unworried about change. The functionalist paradigm assumes that people's perceptions are fixed and they have the same worldview (mental models). The other assumption from an IT adoption point of view is that the requirements and needs of IT adoption already exist and will be discovered through analysis. The perceptions of stakeholders are not required as their views are treated as subjective and irrational. The management assumes to know the requirements and needs of the system.

\subsection{The Interpretive Paradigm (Subjective- regulation)}

This paradigm seeks to understand the subjective world in terms of processes. The social situation's meaning is understood through the interpretation of individual perceptions of viewing things. The goal of intervention is to assist members to reframe events as part of understanding the problem situation. The interpretive paradigm is based on the assumption that organizations are social constructs which are part of human interaction [16]. The interpretive paradigm assumes that organizations' agreements are reached through consensus with no radical change to the status quo. The consensus emerges as part of social constructs through human interaction and reality is intangible as it is part of human consciousness and subjectivity.

The way of interaction, communication and a language used are is important to reach consensus on problem situation. The interpretive paradigm's assumption of a problem situation is that requirements and needs of IT adoption are social constructs. The IT adoption requirements emerge through change of stakeholders' worldviews as they learn from each other's different perspectives. The stakeholders close to the problem situation are assumed to be more knowledgeable about the problem situation and are best to be consulted to build the requirements [16].

\subsection{Radical Structuralist Paradigm (Objective-Radical Change)}

The radical structuralist paradigm's assumption is that political and economic crises within society's inherent structural conflicts are responsible for constant change. The world we live in is viewed as unjust and untenable because of underlying contradictions and regularities [16]. The intervention strategy needs to be integrated at all levels to achieve transformation change of the distressed social system. The assumption of the radical structuralist paradigm is that social conflicts shape the organizations. The social conflicts are caused by the oppression of other parties which may result in radical change as the oppressed try to free themselves. The reality is viewed as objective and concrete, which arises from the social conflict among different stakeholders [16].

The radical structuralist paradigm is characterised by power domination which results in conflicts and instability in organizations. The social conflicts which always exist have a potential for radical change as the oppressed seek to escape from the control [16]. The assumption of a radical structuralist paradigm on IT adoption is that the stakeholders do not have expertise with regard to their requirements and needs. Their requirements and needs are built by representatives. The stakeholders are treated as less knowledgeable in terms of their requirements and needs on IT adoption decision making issues.

\subsection{Radical Humanist Paradigm (Subjective-radical change)}

The concern of a radical humanist paradigm is the removal of social constructs that limits human potential in organizations. Theorists of this paradigm see the need for radical change to improve the existing situation [16]. Organizations are not seen as stable as they are liable to change caused by human social consciousness. The radical humanist paradigm is based on subjectivist reality with potential for radical change as part of transformation [16]. The main agenda of change is the freeing of humans from impediments that limit their full potential. The paradigm views large institutions as full of controls of social opportunities and ideologies which marginalize other members of the social system. Social interventions help to change economic and social structures.

The radical humanist paradigm sees change as healthy for the organizations to survive [16]. The subjective perceptions and interests of different stakeholders are accommodated. The ease of adaptability ensures flexibility to change and has a potential to emancipate stakeholders. The IT adoption requirements and needs of an intervention are part of social constructs of subjective interests and the perspectives of stakeholders are accounted for through debates to reach mutual agreements. The paradigm encourages debates on subjective viewpoints from individuals providing opportunity for creativity. Debates on interventions to problem situations are done without restraints.

\section{SYSTEMS APPROACHES}

According to Cordoba [11], systems approaches encourages the analysis of stakeholder perspectives prior to IT adoption and it allows for reflection to occur on possible improvements. The appreciation of interdependencies among elements of systems following systems approaches is vital as it improves on IT adoption decision making, since this in turn reduces the chances of overlooking important elements [18]. Checkland [8] points to information systems as being social artifacts that people can shape according to their interests and a particular context. He urges managers to take a holistic approach rather than a functionalistic approach when addressing problem situations. 
IT researchers have been urged to become more aware of different strengths and weaknesses of different methodologies [18]. Systems approaches focus on addressing stakeholder needs at the expense of technology demands [8].

Jokonya and Hardman [20:2] write that "systems approaches avoids hardening of some taken-for-granted assumptions that influence decision making in organizations as it enables collective reflection and debate on implication that the decision may have for different stakeholders". Systems approaches assist organizations in reconciling different views of stakeholders in problem situations [8]. Organizations have been urged to view IT adoption decision making as a social phenomenon which needs systems approaches to reveal competing interests among stakeholders [23].

The need for a multi-disciplinary (social and natural sciences) approach by organizations to address complex IT adoption decision making and information systems challenges has been highlighted by many researchers, e.g. Katy and Boyack [21]. While the laws of natural science are deterministic, social practices are agreed upon by people as they adapt [21]. A systems approach is pluralistic in nature as different stakeholder interests are accommodated and compromises are struck [18].

Systems approaches helps to include (sweep in) as many factors as possible of a problem situation looking from different perspectives (worldviews). "A systems approach begins when first you see the world through the eyes of another" [9:231]. Systems approaches emphasises understanding the whole as opposed to the parts in order to understand the relationships. Systems approaches are focused on understanding problem situations in order to improve the situations not solve the problem [33]. Systems approaches are an inquiry process into complex problem situations with interrelated multiple factors and human interests.

Systems approaches as an inquiry process helps to deal with complex problem situations which are not clear from the start as it is part of learning process to reach a resolution. The Systems of Systems Methodology (SOSM) Figure 2 provides a guide on how systems approaches can be applied to address a problem situation. SOSM classifies systems approaches based on the matrix of complexity of a problem situation (simple or complex) and the degree of shared purpose of stakeholders (unitary, pluralist and coercive relationships) [18].

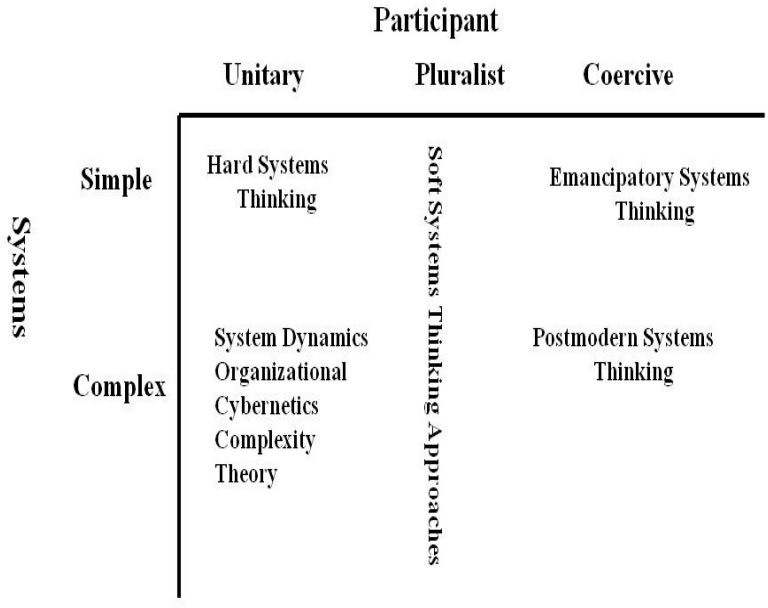

Figure 2. Systems approaches related to problem contexts in the Systems of Systems Methodologies (SOSM) [18].

Systems approaches help reveal various ways in which problem contexts might be typified by managers and management scientists. The development of different systems approaches was governed by particular ideal-type views of the nature of problem contexts. Jackson [18], classified system approaches into four main types based on the nature of problem context they address. Types are goal seeking and viability (hard systems thinking); exploring purposes (soft systems thinking); ensuring fairness (emancipatory systems thinking) and promoting diversity (postmodern systems thinking). Figure 3 shows the relationships between sociological paradigm and systems approaches.

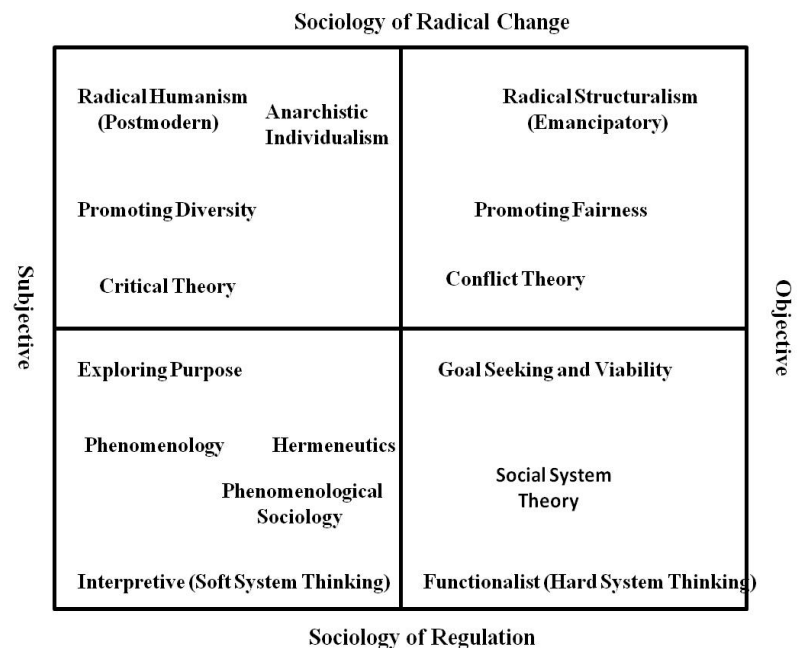

Figure 3. Relationship between sociological paradigms and systems approaches

\subsection{Hard Systems Thinking Approaches}

The hard systems thinking approach using Burrell and Morgan's (1979) framework of sociological paradigms is situated in the functionalist paradigm since its guiding assumptions are objective and regulation [18]. The organizational world is seen as having clearly identifiable purpose made up of systems which can be objectively studied. The hard systems thinking is also known as the goal seeking and viability systems approach (system dynamics, organizational cybernetics and complexity theory) [18].

The hard systems thinking (functionalist) approaches focus on an objective problem while failing to address a human activity situation which is unstructured [7]. The hard systems thinking approaches have an emphasis on prediction and control to achieve desired objectives which are outside human observation [7]. It is premised by the assumption that participants have clear, agreed-upon objectives to improve on the current problem situation. The problem with a hard systems thinking approach is that problem situations rarely present themselves with clear or well-defined goals and objectives [19]. The hard systems thinking perspectives are focused on objective problem issues and problem situations where unity of purpose is perceived to exist.

Katy and Boyack [21] claim that while hard systems thinking (functionalist) approaches have been very successful in simple problem situations they have limited applicability in subjective social systems like IT adoption decision making. Hard systems thinking approaches are based on reductionist approaches which assume that objectives are always clear and problems are viewed as being decomposable and each component may be understood independently [21]. The hard systems thinking approaches fails to appreciate an organization's social, cultural and economic aspects or its complex matrix dimension [21]. IT adoption decision making ought not to be viewed through a simplistic lens of reductionism but by an augmented systems approaches aimed at exploring stakeholder interests [21]. 
Most societal problems arguably cannot be solved by decomposing them into independent sub problems; rather they need to be viewed holistically [21]. Traditional problem solving methodologies believe that every problem situation can be analyzed by the scientific cause and effect relationship where outcomes are mostly predictable, yet such an approach is not suitable for complex systems such as IT adoption in organizations [18]. The hard systems thinking's view that systems can be understood from isolated parts may no longer be applicable to today's complex organizational problems [19]. Managers have been advised not to treat IT adoption decision making as simply being technical and linear in nature but as being complex and unpredictable [25]. The main failure of the hard systems thinking approach is its inability to deal with pluralism.

Most literature on IT adoption decision making pays much attention to a hard systems approach of efficiency and effectiveness, thereby largely failing to acknowledge the complexities of modern organizations [3]. Hard systems thinking approaches seem inadequate to deal with today's modern and complex enterprises. Most hard systems thinking approaches are more concerned with the implementation of the technology and not with how decisions are made on IT adoption [17]. Managers have been criticized for treating organizations as unitary systems with deterministic goals and objectives [18]. Systems approaches challenge this mechanistic, linear view of organizations because the modern organization is largely unpredictable in nature [9].

\subsection{Soft Systems Thinking Approaches}

The soft systems thinking using Burrell and Morgan's (1979) framework is situated within the interpretive paradigm since its guiding assumption is subjective and regulation [18]. Soft systems thinking is also classified as exploring purpose type of systems approaches [18]. Soft systems thinking seek stakeholders' agreement with regard to aims and objectives on issues of concern. The emphasis is on capturing the possible perceptions of the world which becomes more subjective. It helps to structure debate about action to be taken and reach consensus. It has been criticized for its failure to promote genuine debate which makes it regulative in nature. The success of any intervention to problem situation is enhanced by open participative debate between interest groups with equal access to power resources.

The soft systems thinking approaches are focused on issues where people have different perspectives to the problem situation. According to Checkland [8] soft systems methodology seeks to institutionalize learning through the continual seeking of accommodation between the world views of the different stakeholders concerned with a problem situation. The emphasis is on how to cope with ill structured problems by exploring them with different perspectives that exist in people's minds. Multiple views of reality are admitted and their implications are examined. People's actions are mostly determined by the mental models and their interactions with others in the organization and social system.

Soft systems thinking (interpretive) approaches are based on the assumption that knowledge can be obtained from interpreting human thoughts and the feelings of participants through debating and discussing the problem situation [18]. The methodology that forms part of soft systems thinking approaches accepts humans as having different perspectives about a problem situation and that individual worldviews are not the same. An interpretivist acknowledges that truth is subjective and that every worldview may be very restrictive [20]. Soft systems thinking approaches aims to structure and enhance debate but do not address any coercive problem context [18]. The soft systems thinking have limited application to problem situation adopting a radical perspective where conflict or unequal access to power exists.

According to Cordoba [11] the interest in the study of information systems in organizations has shifted to social issues (soft systems) rather than technical issues (hard systems). Therefore, addressing a variety of soft issues has become important in information systems in an attempt to facilitate a more effective use of an information system [11]. Most IT adoption challenges are multifaceted in nature due to the inherent socio-technical complexities of the modern information system [10]. Although most literature recognizes that IT adoption challenges are related to soft (social) issues, most of IS research is still focused on hard (technical) issues $[11,20]$. Managers have been advised to balance the hard and soft system models to achieve efficiency and flexibility in organizations [19, 34, 35].

\subsection{Emancipatory Systems Thinking Approaches}

Emancipatory systems thinking using Burrell and Morgan's (1979) framework is situated within the radical structural paradigm since its guiding assumption are objective and radical change [18]. Emancipatory systems thinking is also known as an ensuring fairness type of approach [18]. The emancipatory systems thinking which is based on the radical structural paradigm focuses on three commitments: critical awareness, social awareness and emancipation.

Emancipatory systems thinking was developed because of the failure of functionalist and interpretive systems to give appropriate attention problem situation of coercive nature. The emancipatory systems thinking approaches emphasize the emancipation and empowerment of those discriminated against with the existing system in terms of the way they are treated [18]. Emancipatory systems thinking emphasises problem situations which are perceived to have issues of power relations that affect the problem situations.

Some of the emancipatory systems thinking approaches are critical systems heuristics and team syntegrity. Fairness in organizations is important for full participation of all members in decision making. Emancipatory systems thinking therefore focuses attention on matters that can easily be missed by hard systems thinking and soft systems thinking [18]. They are of huge significance to organizations and their success is measured by empowerment and emancipation of the disadvantaged

Emancipatory systems thinking approaches focuses on improving real-world problem situations by revealing forms of alienation and oppression in asocial designs [18]. The alienation and oppression problem situation is addressed by allowing everyone to participate. The intervention strategy helps the alienated and oppressed to take responsibility for their liberation. The successes of emancipatory systems thinking are evaluated in terms of empowerment and emancipation.

\subsection{Postmodern (Critical) Systems Thinking Approaches}

The postmodern (critical) systems thinking using Burrell and Morgan's (1979) framework is situated within the subjectiveradical humanist paradigm since its guiding assumption are subjective and radical change [18]. Critical systems thinking approaches are also known as the diversity systems approach types [18]. The postmodern systems thinking approach focuses on five commitments: critical awareness, social awareness, 
emancipation, theoretical pluralism and methodological pluralism. One of the benefits from critical systems thinking is the complementary strengths of social theory and systems thinking in problem solving [18]. Many organizations are faced with challenges of diversity due to the nature of the operations.

The critical systems thinking approach assumes that problem contexts are deemed to be extremely complex and too hard to understand and participants are regarded as subject to power relationships they cannot control [18]. The critical systems thinking approach's perspective of organizations is that they are too complex to understand using any one methodology and disagrees on claims of guaranteed generalized improvement and encourages the surfacing of suppressed viewpoints. Critical systems thinking as a postmodern approach allows relevant stakeholders to express their diversity and allow for marginalized voices to be heard.

Jackson [19:136] highlights that "Critical systems thinking accepts hard systems thinking (based on positivism) as an equal partner to soft systems thinking (based on interpretivism), as well as encouraging the extension of applied systems thinking into the domains of emancipatory and postmodern paradigms". Critical systems thinking addresses the weaknesses of hard systems thinking and soft systems thinking, using social theories with commitment to critique, emancipation and pluralisms. Critical systems thinking approaches help organizational stakeholders to design a better human social system by exploring alternative designs [19].

Since critical systems thinking, based on pluralism, embraces diverse interests and values, it empowers stakeholders by having them participate in decision making [18]. According to Jackson [19:138] “critical systems researchers do not claim to know the answer in advance or peddle the same solution to all problems in all circumstances”. In addition Jackson [19] notes that "if management scientist[s] are genuinely to become competent in analyzing complex problems and intervening to resolve them, then the road marked out by critical systems thinking and practice is the one on which our discipline must progress" [19:138].

\section{PROPOSED FRAMEWORK}

This section presents our enhanced framework for IT adoption decision making in organizations. Figure 4 illustrates the components of the framework and their relationships to IT adoption decision making in organizations. The proposed framework is made up of four integrated components. These are: IT Governance, Stakeholders, a Technology Acceptance Model and Sociological Paradigms, Systems Approaches. The framework assumes that there is no one methodology suitable for all IT adoption problem situations. In addition, it is accepted that various stakeholders have different worldviews in terms of organizational IT adoption. It is therefore necessary to explore IT adoption problem situations using various sociological paradigms to determine the most suitable methodology for a given situation.

It is anticipated that the proposed framework will assist in addressing various stakeholder issues on IT adoption in organizations, e.g. it provides for mechanisms to consider and accommodate different stakeholder input on IT adoption decision making. Such move will empower stakeholders in IT adoption strategies as part of addressing the decision-making problem discussed in this paper. Our framework is expected to facilitate the understanding of a problem situation before fixing on an IT adoption strategy in an organization.
Brief discussions of the framework in Figure 4 follow in sections $6.1-6.9$.

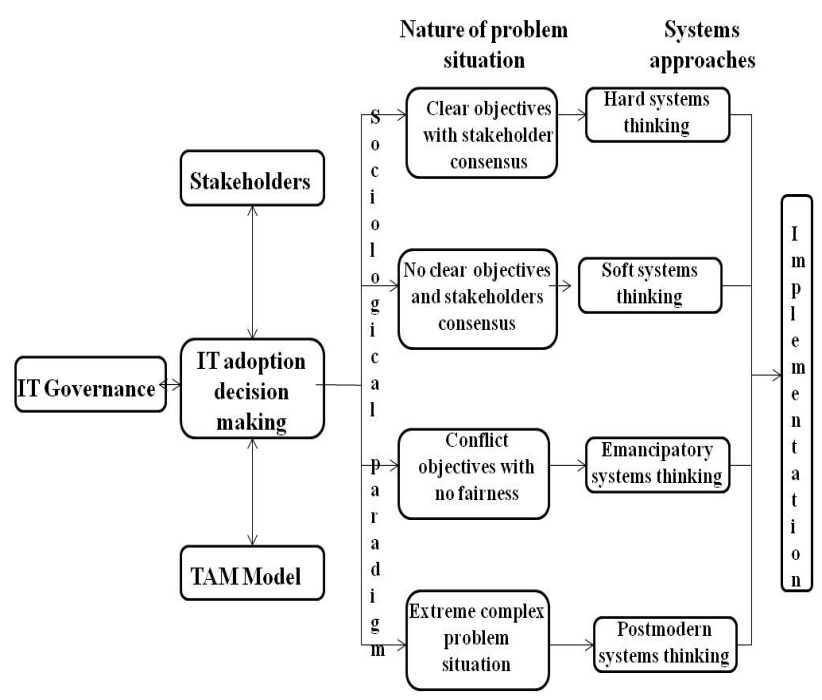

Figure 4. IT adoption decision making framework

\subsection{IT Governance Component}

IT governance in our framework is expected to assist with aligning business objectives with IT adoption decision making in the organization. Good IT governance aims to have the required controls in place as part of IT adoption decision making in the organization. The IT governance component, therefore, helps to achieve a balanced governance structure for adoption decisions. The structure should also assist organizations in balancing the diverse IT adoption needs of multiple stakeholders.

\subsection{Stakeholder Component}

From a stakeholder perspective, the organization's response to the environment may result in taking a decision that is not supported by (all) the stakeholders. Stakeholders may be internal or external to an organization, e.g. suppliers, business partners, customers, employees, etc. The impact of IT adoption will vary for the different stakeholder groups in the organization; hence the identification of stakeholders who might be impacted by the IT adoption is important for the success of the adoption exercise. The different stakeholder groups may also have different perceptions about the benefits of IT adoption in the organizations.

\subsection{Technology Acceptance Model Component}

The Technology Acceptance Model (TAM) has been found to be useful in understanding individual behaviours in IT adoption. The two TAM constructs, perceived usefulness and perceived ease of use are important determinants in IT adoption from an individual perspective as opposed to an organizational perspective. TAM therefore helps one to understand individual behaviour on IT adoption. IT adoption in an organization is complex in nature as it involves individuals with different perspectives. Therefore, it is important to distinguish an individual perspective from an organizational perspective when adopting IT. IT adoption in an organization is a two phased approach which involves first the organizational adoption before any individual adoption of the technology. While the particular adoption may have advantages for the organization, it might not be the case for individuals. 


\subsection{Sociological Paradigm Component}

The sociological paradigm component should assist with understanding the nature of the problem situation before IT adoption decision making takes place in the organization. IT adoption in an organization is part of an intervention strategy to address an existing problem situation. The four sociological paradigms (functionalist, interpretive, radical structuralist and radical humanist) are based on different perspectives of a problem situation. The understanding of the nature of the situation is vital in selecting the appropriate methodology to address the adoption strategy. In some cases the problem situation may require the use of more than one methodology as pointed out before.

\subsection{Hard Systems Thinking Component}

The hard systems thinking component is suitable for an IT adoption problem situation that is targeted at improving efficiency and efficacy in a scenario having set goals and objectives. Hard systems thinking approaches to IT adoption assume that organizations can be understood using cause and effect relationships; and they rely on such relationships to resolve problem situations. The assumptions are that there are fixed agreements on the set of objectives for IT adoption in the organization.

The hard system component in the framework will address problem situations that have clear objectives or when there is consensus among stakeholders in the organization. The issue becomes "How" to do it, which can be resolved by hard systems thinking approaches, as opposed to the "What" question. The nature of a problem situation may involve an improvement of an existing process in the organization. In some cases the main objective of the IT adoption intervention in an organization could be to improve efficiency. The hard systems thinking approach normally fails to appreciate the complexities of IT adoption when dealing with problem situations of a social nature. The challenges of dealing with pluralistic problem situations result in the need for a soft systems thinking approach to IT adoption in an organization.

\subsection{Soft Systems Thinking Component}

The soft systems thinking (interpretive) component is suitable for problem situations where there is little agreement on objectives and a need exists to debate the problem situation among stakeholders. The soft systems thinking approaches accommodate different perceptions from stakeholders to an IT adoption situation. The soft systems thinking approaches do not assume the existence of clear goals to IT adoption decision making before intervening with the problem situation. The soft systems thinking approaches assist by exploring the nature of the problem context through learning from those involved in the social design.

The soft systems thinking component is suitable for problem situations where there are no clear objectives or agreement among the stakeholders in the organization. In order to agree on objectives it may be necessary to debate among those involved or affected by the adoption exercise. But the assumption is that the environment will be conducive to discussing IT adoption without coercive effects.

\subsection{Emancipatory Systems Thinking Component}

In situations where there are coercive problems, an emancipatory systems thinking component may assist to have the voice of the oppressed be heard. Emancipatory systems thinking helps disadvantaged stakeholders (affected but not involved) to participate in IT adoption decision making. In cases where there is discrimination among stakeholders; emancipatory systems thinking empowers those disadvantaged by the social design.

Emancipatory systems thinking open democratic debates on issues affecting disadvantaged groups and makes their voices heard. Emancipatory systems thinking attempts to ensure genuine participation of stakeholders on IT adoption decision making without a coercive element. Naturally, without the affected stakeholder being empowered, there will be no genuine participation. It fosters the involvement of the affected in the discussion of IT adoption decision making in the organization.

\subsection{Postmodern (Critical) Systems Thinking Component}

In situations where the problem situation is too complex it may be necessary to use more than one methodology as part of critical systems thinking. The insight from critical systems thinking is that each methodology has a weakness which can be compensated for by the strength of another methodology. The postmodern (critical) systems thinking approaches promote the accommodation of a greater diversity of methodologies involved in IT adoption decision making in organizations.

Postmodern (critical) systems thinking approaches provide an alternative way to encourage different methodologies to explore the IT adoption problem situation. In addition to promoting pluralism of methodologies, they promote the use of complementary methodologies in addressing complex IT adoption problem situations. The use of postmodern systems thinking approaches to IT adoption in an organization promotes rigour in an intervention strategy.

\subsection{Discussion}

The proposed framework acknowledges that IT adoption in any organization is a complex social phenomenon. In order for organizations to benefit from IT adoption it is important to acknowledge that the benefits of IT adoption depend on individual worldviews. The proposed framework suggests the need for understanding the nature of the IT adoption problem situation before making decisions to implement the technology in the organization. We argued in this paper that the different sociological paradigms are well suited for addressing the different natures of problem situations. System designers are therefore advised that the one size fits all approach is not applicable to IT adoption decision making. IT adoption problem situations need to be viewed in their own organizational context.

Our framework challenges organizations to understand the problem context in order to find a set of suitable methodologies to solve the problem. Hard systems thinking approaches may not be suitable for problem situations with no clear objectives. The four subcomponents of the sociological paradigm provide guidelines for selecting the appropriate set of methodologies for the problem situation at hand. The different methodologies are suitable for different problem contexts.

The use of our framework implies that an IT adoption decision making process will involve many stakeholders, resulting in their buy-in. The proposed framework also allows for an iterative process to take place whereby methodologies are tested on one problem situation. In summary the framework advocates that:

- The most suitable methodology is used for the problem situation at hand.

- The affected and/or involved stakeholders have input in the IT adoption decision making process. 
- $\quad$ The stakeholders feel part of the IT adoption process.

- The IT adoption process addresses concerns of the different stakeholders.

As part of future work each component of our framework has to be further developed after which it has to be validated in an organization where IT adoption has been implemented during the past six months. The framework may also need to be validated using an action research study to discover its effectiveness in addressing IT adoption issues in an organization.

\section{CONCLUSION}

This paper argued the case that IT adoption decision making is a complex endeavour which requires a multi-methodological approach. While traditional approaches based on a simplistic lens of reductionism were successful in addressing simpler functionalist problem situations, they are not suitable for addressing highly complex problem situations associated with IT adoption decision making. The paper showed that a single approach does not fit all problem situations, highlighting the need for a multi-methodology approach to complex problem situations. The diversity of methodologies should not be seen as a crisis, but a realization that different problem situations require different methodologies [19].

From the above discussions and through an analysis of the other popular frameworks, we defined our own framework which has the potential to further assist in IT adoption decision making in an organization. The proposed framework addresses issues affecting IT adoption in organizations such as stakeholder participation and securing their buy-in. Some of the components of the framework are already used in IT systems development, thereby facilitating their integration into the larger framework. A limitation of our framework is the requirement for it to be evaluated in an organizational context which is part of future work. In addition, validating the framework using practitioner longitudinal research may also be important.

\section{REFERENCES}

[1] Beale, R. 2007. Slanty Designs Communications of the ACM 50 (1), 21-24 doi >10.1145/1188913.1188934

[2] Benbasat, I. and Barki, H. 2007. Quo vadis TAM? Journal of the Association for Information Systems (JAIS) Volume 8 Issue 4. Article 3 211-218

[3] Bernroider, E. W. N. 2008. IT governance of enterprise planning supported by the Delone-Mclean model of information systems success-Information and management 45 257-269 doi>10.1016/j.im.2007.11.004

[4] Bose, R and Luo X. 2011. Integrative Framework for assessing firm's potential to undertake Green IT initiatives via virtualization - A Theoretical perspective. Journal of strategic Information Systems 20 (2011) 3854 doi:10.1016/j.jsis.2011.01.003

[5] Bouwman, H.; Van Dijk, J.; Van den Hoof, B. and Van de Wijngaert, L. 2005. Information and Communication Technology in Organizations: adoption, implementation, use and effects. London, UK: Sage

[6] Brynjolfsson, E. and Hitt, L. 1998. Beyond the Productivity Paradox, Communications of the ACM, Vol. 41, No. 8 49-55.

[7] Burrell, G. and Morgan, G. 1979. Sociological Paradigms and Organizational Analysis. London, UK: Heinemann
[8] Checkland, P. 1990. Information systems and systems thinking: time to unite? In: Soft Systems Methodology in Action, Checkland, P. \& Scholes, J. (eds.), 303-315. Chichester, UK: John Wiley

[9] Churchman, C. W. 1968. The Systems Approach. New York, NY: Basic Books

[10] Conlon, P. and Carew, P. 2005. A Risk Driven Framework for Open Source Information Systems Development In: Scotto, M. \& Succi, G. (eds) Proceedings of the 1st International Conference on Open Source Systems. 11-15 (July 2005), Genova, Italy. 200203.

[11] Cordoba, J. R., 2009. Critical reflection in planning information systems: A contribution from critical systems thinking, Information Systems Journal, (19.2) 123147.doi:10.1111/j:1365-2575.2007.00284.x

[12] Davis, F. D. 1989. Perceived Usefulness, Perceived Ease of Use, and User Acceptance of Information Technology. MIS Quarterly, 13(3), 319-340.

[13] Delone, W. H. and McLean, E. R. 2003. The Delone and Mclean Model of Information Systems Success: A TenYear Update. Journal of Management Information Systems, 19(4), 9-30.

[14] Du Plooy, N. F. 1998. An Analysis of the Human Environment for the Adoption and Use of Information Technology. DCom Thesis, Department of Informatics, University of Pretoria, Pretoria, South Africa.

[15] Freeman, R. E. 1984. Strategic Management. A Stakeholder Approach Boston MA: Pitman

[16] Hussain Z. and Flynn D. 2002. Validating The Four Paradigm, Theory of Information System Development, Working Paper

[17] Holick, J.; Larsen, M. H. and Pedersen, M. K. 2005. Managerial and Technical Barriers to the adoption of Open Source Software ; 4th International Conference on COTS-Based Software Systems (ICCBSS 2005), Bilbao, Spain.

[18] Jackson, M. C. 2003. Systems Thinking: Creative Holism for Managers, Chichester, UK: John Wiley and Sons.

[19] Jackson, M. C. 2010. Reflections on the Development and contributions of Critical Systems Thinking and Practice System Research and Behavioural Science 27 133139

[20] Jokonya, O. and Hardman, S. 2011. Boundary Critique and Stakeholder Collaboration in Open Source Software Migration: A Case Study, International Journal of Sociotechnology and Knowledge Development, October December, Vol. 3 No. 4 1-13 doi: 10.4018/jskd.2011100101

[21] Katy B. and Boyack K. W. 2010. Mapping Interdisciplinary Research, In Robert Froderman, Julie Thompson Klein and Carl Mitchan EDS. Oxford Handbook of Inter-disciplinary Ch. 31 457-460 New York: Oxford University Press.

[22] Kim, E.; Shin, S. and Lee B. 2009. An empirical analysis of risk taking behaviour in IT platform migration decision, Journal of Computers in human, Volume 25 issue 6 1290-1305 The Netherlands, B. V. Amsterdam: Elsevier Science Publishers doi $>10.1016 /$ j.chb.2009.07.004 
[23] Klecun, E. and Cornford, T. 2005. A Critical Approach to Evaluation, European Journal of Information Systems 14, 229 - 243. Doi:10.1057/palgrave.ejis.3000540

[24] Lawrence J. 2010. The Factors that influence Adoption and usage Decision in SMEs: Evaluating Interpretive Case Study Research in Information Systems. The Electronic Journal of Business Research Methods Volume 8 Issue 12010 (51-62), available online at www.ejbrm.com

[25] Lyytinen, K. and Newman M. 2008. Explaining information systems change: a punctuated socio-technical change model. European Journal of Information Systems17 589-613

[26] Magnusson, J.; Klingberg, J.; Enquist, H.; Oskarsson, B.; Nilsson, A. and Gidlund, A. 2010. All Aboard: ERP Implementation as Participatory Design AMCIS 2010 Proceedings Paper 253

[27] Martins, L.M., Moura, A., Cunha, P.R.D., Figueiredo, A. D. D.: Selecting and Ranking IT Governance Practices for Electric Utilities; In AMCIS 2010 120-120

[28] Mirza, A. A. 2010. Critical Success and Failure Factors in a Charitable Organization's Systems Development and Adoption AMCIS 2010 Proceedings Paper 381

[29] Morgan G. 1980. Paradigms, Metaphors and Puzzle solving in organizational theory. Administrative Science Quarterly, 251980605

[30] Musson, D. 2009. IT Governance: A Critical Review of the Literature. In: CATER-STEEL, A. (ED). Information Technology Governance and Service Management: frameworks and adaptations. Hershey: Information Science Reference, 2009. P.6380

[31] Oliveira T. and Martins M. F. 2011. Literature Review of Information Technology Adoption Models at Firm Level. The Electronic Journal Information System Evaluation Volume 14 Issue 12011 (110-121) available online at www.ejise.com

[32] Pan G. 2009. Examining Stakeholders Roles in Influencing IT Project Cancellation Decisions, In T. T. Kidd (Ed.), Handbook of Research on Technology Project Management Planning, and Operations. (92104). Hershey, PA: IGI Global. doi: 10.4018/978-160566-400-2.ch011

[33] Reynolds, M. and Holwell S. 2010. Introducing approaches. In: Reynolds, Martin and Holwell, Sue eds. Systems Approach to managing Change: A Practical Guide. London: Springer, 1-23

[34] Silvius A. J. G. 2009. Project Management 2027: The Future of Project Management. In T. T. Kidd (Ed.),
Handbook of Research on Technology Project Management Planning, and Operations. (17-36). Hershey, PA: IGI Global. doi: 10.4018/978-1-60566-4002.ch011

[35] Skulmoski, G. J. and Hartman, F. T. 2009. The Progression Towards Project Management Competence. In T. T. Kidd (Ed.), Handbook of Research on Technology Project Management Planning, and Operations. (37-57). Hershey, PA: IGI Global. doi: 10.4018/978-1-60566-400-2.ch011

[36] Surry, D. W. 2009. Bringing the user into the product development process. In T. T. Kidd (Ed.), Handbook of Research on Technology Project Management Planning, and Operations. (107-115). Hershey, PA: IGI Global. doi: 10.4018/978-1-60566-400-2.ch011

[37] Tornatzky, L. and Fleischer, M. 1990. The process of technology innovation, Lexington, MA, Lexington Books.

[38] Ulrich, W. 2001. The quest for competence in systemic research and practice. Systems Research and Behavioral Science, 18, No. 1, 3-28

[39] Ven, K., Haes S., Grembergen W. and Verelst J. 2008. Using COBIT 4.1 to Guide the Adoption and Implementation of Open Source Software, Information Systems Control Journal, Volume 3, 2008

[40] Verner, J. M. and Cerpa, N. 2005. Australian Software Development: What Software Project Management Practices Lead to Success? Australian Software Engineering Conference (ASWEC'05), 2005, 70-77 doi>10.1109/ASWEC.2005.14

[41] Waddell, S. 2005. Societal Learning and Change - How Governments, Business and Civil Society are Creating Solutions to Complex Multi-stakeholder Problems. Sheiffield: Greenleaf Publishing

[42] Weilbach, L. and Byrne, E. 2010. A human environmentalist approach to diffusion in ICT policies. A case study of the FOSS policy of the South African Government, Journal of Information, Communication and Ethics, Vol. Issue 1 108-123. DOI: $10.1108 / 14779961011024837$

[43] Weill, P. 2004. Don`t Just Lead, Govern: How TopPerforming Firms Govern IT. MIS Quarterly Executive, Minnesota, Vol. 3, n. 1, 1-17

[44] Weill, P. and Ross, J. W. 2005. A matrixed approach to designing IT governance. MIT Sloan Management Review, 46(2), 26-34. 